\title{
LA SUSPENSIÓN DE LA EJECUCIÓN DE LA PENA Y LA RESPONSABILIDAD CIVIL. EL PRINCIPIO "ALTERUM NON LAEDERE" Y LA DESPROTECCIÓN DE LAS VÍCTIMAS Y PERJUDICADOS ${ }^{1}$
}

\author{
Miguel Ángel Moreno Navarrete \\ Profesor Contratado Doctor (Titular Acreditado) \\ Departamento de Derecho Civil de la Universidad de Granada
}

Email: mmnavarrete@ugr.es

RESUMEN: El artículo 81.3 del Código Penal dispone que, para que pueda aprobarse por el juez la suspensión de la ejecución de la pena privativa de libertad: "se hayan satisfecho las responsabilidades civiles que se hubieren originado, salvo que el Juez o Tribunal sentenciador, después de oír a los interesados y al Ministerio Fiscal, declare la imposibilidad total o parcial de que el condenado haga frente a las mismas". Entendemos que dicha excepción puede desproteger a víctimas y perjudicados por el incumplimiento del principio alterum non laedere.

PALABRAS CLAVE: responsabilidad civil, suspensión, pena de prisión.

ABSTRACT: The article 81.3 of the Criminal Code say that, for the approval by the judge of the suspension of the execution of the sentence of prison, "for the civil liabilities arising to have been paid, except if the Judge or Court of Law sentencing, after hearing the parties concerned and the Public Prosecutor, declares that it is fully or partially impossible for the convict to honour these". We understand that the victims and injured parties can stay unprotected by the principle alterum non laedere, by application of that Article.

KEYWORDS: torts, civil responsibility, suspensión of sentence, jail sentence.

1 El presente artículo ha sido realizado en el marco del Proyecto de Investigación, financiado por el Ministerio de Ciencia e Innovación, DER2012-35860 "Variables para una moderna política criminal superadora de la contradicción expansionismo-reduccionismo de la pena de prisión". 


\section{ESTADO DE LA CUESTIÓN.-}

El artículo 80 del Código Penal dispone que los jueces o tribunales podrán dejar en suspenso la ejecución de las penas privativas de libertad no superiores a dos años mediante resolución motivada, si bien, la suspensión de la ejecución de la pena no será extensiva a la responsabilidad civil derivada del delito o falta.

De esta forma, la responsabilidad civil derivada del delito no es exonerable, al mismo tiempo que, su cumplimiento, se convierte en requisito indispensable para el otorgamiento de la suspensión. El artículo 81 del Código Penal al enunciar las condiciones que deben apreciarse por el Juzgador a la hora de su aprobación, su número $3^{\circ}$, dice que: "se hayan satisfecho las responsabilidades civiles que se hubieren originado, salvo que el Juez o Tribunal sentenciador, después de oír a los interesados y al Ministerio Fiscal, declare la imposibilidad total o parcial de que el condenado haga frente a las mismas".

El artículo 81.3 es pues, una excepción al artículo 80 sobre la no extensión de la suspensión a la responsabilidad civil, ya que, el Juez o Tribunal sentenciador, tras de oír a los interesados y al Ministerio Fiscal, la imposibilidad total o parcial de que el condenado haga frente a las mismas.

Es decir, motivadamente, podrá acordarse la medida de suspensión de la pena aunque no se hubiera satisfecho la responsabilidad civil, siempre que, oídas las partes, se declare la insolvencia total o parcial del responsable.

La cuestión es que, dichas normas olvidan a víctimas y perjudicados, pues, en la práctica, el condenado puede evadir la pena privativa de libertad sin el resarcimiento del daño, o lo que es lo mismo, la norma aboga por la ruptura del principio "alterum non laedere". 


\section{EL PRINCIPIO “ALTERUM NON LAEDERE".-}

El jurista romano ULPIANO al enunciar los principios del Derecho, dijo que toda persona deberá vivir honestamente, no dañar a otro y dar a cada uno lo suyo (Ulpiano, Digesto 1.1.10.1, "Iuris praecepta sunt haec: honeste videre, alterum non laedere, suum cuique tribuere").

Del mismo modo, el principio general según el cual "nadie puede dañar a otro" se enuncia también con la máxima: "Neminem laedere".

Fueron los juristas de la Escuela de Bolonia, quienes al tratar la doctrina del jurisconsulto GAYO aportaron matices fundamentales a la máxima de ULPIANO, diciendo que "el que hace uso de su derecho no perjudica a nadie"2.

Esta máxima, en realidad, no es del todo cierta hoy en día, pues nuestro Ordenamiento jurídico obliga a que los derechos se ejerzan de buena fe, la cual se presume $^{3}$. Pues, la Ley no ampara las actuaciones de los sujetos, que siendo acordes al ejercicio de un derecho propio, y bajo ciertas circunstancias, cause daño a tercero, pues, en este caso, surgirá el deber de indemnizar por dicho daño causado ${ }^{4}$.

El principio "alterum non laedere" puede explicarse a partir de la doctrina de la relación jurídica y el derecho subjetivo.

En general, la doctrina de la relación jurídica nos explica como los sujetos de derecho se vinculan en una relación de deber-poder, donde uno de ellos queda obligado con el otro a la realización de una determinada prestación, consistente en dar, hacer o no hacer ${ }^{5}$.

\footnotetext{
${ }^{2}$ Gl. a GAYO en Instituta 1.53, "Neminem laedit, qui suo iure utitur".

${ }^{3}$ Artículo 7.1 Código Civil, "Los derechos deberán ejercitarse conforme a las exigencias de la buena fe" ${ }^{4}$ Artículo 7.2 Código Civil, "La ley no ampara el abuso del derecho o el ejercicio antisocial del mismo. Todo acto u omisión que por la intención de su autor, por su objeto o por las circunstancias en que se realice sobrepase manifiestamente los límites normales del ejercicio de un derecho, con daño para tercero, darálugar a la correspondiente indemnización y a la adopción de las medidas judiciales o administrativas que impidan la persistencia en el abuso"

${ }^{5}$ Artículo 1089 Código Civil, "Las obligaciones nacen de la ley, de los contratos y cuasi contratos, y de los actos y omisiones ilícitos o en que intervenga cualquier género de culpa o negligencia; Artículo 1088 Código Civil, "Toda obligación consiste en dar, hacer o no hacer alguna cosa".
} 
El hecho, acto o negocio jurídico es generador de un binomio derecho-obligación respecto de los sujetos de tal manera que su explicación teórica puede reducirse a lo siguiente: Si alguien tiene un derecho subjetivo es porque otro (o "todos", el resto de sujetos del mundo) tiene o tienen una obligación. El caso es que esto puede explicarse de dos formas: Como el nacimiento de una obligación de una parte; o, desde el punto de vista de la otra parte, como el nacimiento de un derecho subjetivo.

De esta forma, a partir de la teoría de la relación jurídica, se puede explicar el nacimiento de los derechos subjetivos, los cuales, dependiendo del derecho de que se trate, pueden otorgar a sus titulares: Potestades, facultades, pretensiones y acciones. La principal es la facultad de ejercicio, pero el derecho otorga la obligación de otro de dar, hacer o no hacer (respetar), por lo que, el sujeto tendrá siempre la "pretensión", de tal forma que puede exigir dicha obligación. Ahora bien, si dicha obligación de otro es omitida por los mecanismos propios del tráfico jurídico, el titular del derecho puede exigirlo "en juicio" a través de la "acción".

Este esquema teórico es muy importante para el análisis de cualquier situación, pues determinará los sujetos, el objeto, las pretensiones y las acciones, lo cual se hace muy práctico para el estudio de la responsabilidad civil derivada del delito o falta. Véase el siguiente supuesto: E.g., una persona que conduce a gran velocidad por una vía urbana atropella a un sujeto en un paso de peatones cuando este último cruzaba adecuadamente, produciéndole la muerte.

Si este supuesto se lo comentamos a cualquiera persona, nos diría siempre lo mismo, el conductor tiene la culpa y debe indemnizar. Pero nosotros debemos ir más allá e ir analizando técnicamente este hecho, pues de un examen profundo determinaremos muchos más aspectos de los que podamos imaginar.

Por ahora, nos bastaría con dilucidar si la acción concreta es un hecho, un acto o un negocio jurídico y si existe transcendencia jurídica, o más bien, si existe norma jurídica que incluya en su supuesto de hecho la acción que acabamos de describir.

- Debemos decir que se trata de un hecho, pues ni el conductor ni el atropellado han acordado lo sucedido (negocio jurídico), ni se trata de actos formales que el 
Ordenamiento jurídico le otorga trascendencia jurídica (como es el caso de realizar testamento); sino simplemente un hecho que produce un daño.

- Si se produce un daño y aplicamos la regla de ULPIANO ("alterum non laedere") como una obligación universal de todo ciudadano, la consecuencia es que el conductor tiene (puede tener) responsabilidad penal y, además, ha de reparar el daño causado, es decir, el conductor, debido al hecho, se obliga a reparar; o visto de otro modo, el accidentado, en este caso "sus sucesores", debido al hecho, adquieren un derecho subjetivo.

A partir de dicho hecho, el sujeto productor del daño y el dañado o perjudicado quedan vinculados en una relación de deber-poder que determina la obligación de reparar el daño causado. O dicho de otra forma, quién tiene la obligación tiene el DEBER; y quién tiene el derecho tiene el PODER. El deber se traduce en la obligación de dar, hacer o no hacer; el poder se traduce en el derecho a exigir que se cumpla. Esta unión de dos sujetos con diferentes roles, es justamente la relación jurídica.

La relación jurídica que se establece entre dos sujetos como consecuencia de un hecho que causa daño a otro, en su persona o bienes, es el fundamento técnicojurídico de la responsabilidad civil.

El fundamento último es que, a partir del hecho productor del daño, se ha lesionado un derecho anterior de su titular (o bien jurídico protegido, derecho a la vida) y surge ex novo el derecho a ser indemnizado, es decir, la obligación de otro (agente productor), y por tanto, la pretensión (derecho a exigir que otro realice una prestación: dar, hacer o no hacer); y, en última instancia, la acción (pretensión en juicio: acción de condena, reparación del daño, responsabilidad civil).

Por otra parte, la norma jurídica se coloca en el principio de la pirámide, determinando en cada caso los supuestos de hecho y las consecuencias jurídicas al amparo de la protección de valores y principios. Es decir, el nacimiento de los derechos y de las obligaciones se fundamentan siempre en una norma jurídica. Este es el primer paso que ha de darse en el análisis teórico-práctico de cualquier 
supuesto; muy importante para el caso de la responsabilidad civil. Dependiendo de la clase de norma jurídica y de los bienes jurídicos que protegen, la responsabilidad puede tener diferente carácter: civil, penal, administrativa, etc. En el caso que nos ocupa, el tipo penal.

El origen es el hecho ilícito, es decir, contrario a Derecho, o que intervenga culpa o negligencia. De esta forma, el hecho ilícito por ser contrario a Derecho puede tener: Naturaleza de ilícito penal por dañar un bien jurídico protegido en el orden penal, la responsabilidad en este caso es doble: Responsabilidad civil y responsabilidad penal; Naturaleza de ilícito civil por contrariar normas jurídicas no penales, como civiles y administrativas, en este supuesto la responsabilidad es civil.

\section{LA RUPTURA DEL PRINCIPIO “ALTERUM NON LAEDERE" EN LA FASE DECISORIA DE LA RESPONSABILIDAD.-}

La consecuencia del principio es la obligación de reparar y dicha obligación viene motivada por la producción de un daño sobre un bien jurídico protegido.

La responsabilidad civil derivada del delito o falta se contempla en los artículos 109 y siguientes del Código Penal. Con carácter general, el principio se contiene en dicho primer artículo al dispones que: "La ejecución de un hecho descrito por la Ley como delito o falta obliga a reparar, en los términos previstos en las Leyes, los daños y perjuicios por él causados". Pudiendo optar el perjudicado, en todo caso, "por exigir la responsabilidad civil ante la Jurisdicción Civil”.

El régimen jurídico a aplicar se ha de determinar por "la clase de juicio": Civil o penal. De esta forma, la responsabilidad civil puede ventilarse en el procedimiento civil; y, para el caso de que los hechos fuesen constitutivos de delito o falta, en el procedimiento penal, o en juicio civil separado, mediante la previa reserva de acciones civiles en el propio procedimiento penal.

La acción civil siempre es la misma, lo que difiere es el proceso, civil o penal, con principios y procedimientos muy diferentes. 
En este sentido, dada la capacidad de las víctimas y perjudicados para optar por la jurisdicción civil o penal, la cuestión que hemos de plantearnos, es si el régimen jurídico de la responsabilidad civil que se ordena en el Código Penal es el mismo que la que se determina por las normas civiles, concretamente el Código Civil.

Lo primero que debemos decir es que, la obligación de resarcimiento derivada en un hecho doloso o culposo que causa daño a otro y que constituye delito o falta, se regirá, de acuerdo con el artículo 1092 del Código Civil, "por las disposiciones del Código Penal"6.

A partir de este reenvío normativo, el juez penal deberá resolver conforme a los preceptos del Código Penal, pero, ¿deberá hacerlo el juez civil si víctima o perjudicado optan por dicha vía?

La cuestión no es baladí, pues si nos adentramos en el régimen jurídico que se contiene en el Código Penal, son varios los preceptos que otorgan cierta discrecionalidad al juez penal para modular la obligación de reparación, así:

- El artículo 112 del Código Penal dice que: "La reparación del daño podráconsistir en obligaciones de dar, de hacer o de no hacer que el Juez o Tribunal estableceráatendiendo a la naturaleza de aquél y a las condiciones personales y patrimoniales del culpable, determinando si han de ser cumplidas por él mismo o pueden ser ejecutadas a su costa"; es decir, el juez penal atenderá a las condiciones "patrimoniales" del culpable.

- El artículo 114 del Código Penal dice que: "Si la víctima hubiere contribuido con su conducta a la producción del daño o perjuicio sufrido, los Jueces o Tribunales podrán moderar el importe de su reparación o indemnización"; igualmente, el juez penal podrá “moderar” el importe.

- El artículo 115 del Código Penal, dice que: “Los Jueces y Tribunales, al declarar la existencia de responsabilidad civil, establecerán razonadamente, en sus

${ }^{6}$ Artículo 1092 del Código Civil, "Las obligaciones civiles que nazcan de los delitos o faltas se regirán por las disposiciones del Código Penal”. 
resoluciones las bases en que fundamenten la cuantía de los daños e indemnizaciones, pudiendo fijarla en la propia resolución o en el momento de su ejecución”; del mismo modo, el juez penal “establecerá razonadamente".

- El artículo 118.1.1 a del Código Penal, al tratar la responsabilidad civil de los sujetos en estado enajenación mental, permanente o transitoria, y en los supuestos del alteración de la percepción, hace responsables a "quienes los tengan bajo su potestad o guarda legal o de hecho, siempre que haya mediado culpa o negligencia por su parte y sin perjuicio de la responsabilidad civil directa que pudiera corresponder a los imputables", y continua: "Los Jueces o Tribunales graduarán de forma equitativa la medida en que deba responder con sus bienes cada uno de dichos sujetos".

- El artículo 118.1.3 del Código Penal, en los supuestos de estado necesidad para evitar un mal propio o ajeno lesione un bien jurídico de otra persona o infrinja un deber, "serán responsables civiles directos las personas en cuyo favor se haya precavido el mal, en proporción al perjuicio que se les haya evitado, si fuera estimable o, en otro caso, en la que el Juez o Tribunal establezca según su prudente arbitrio".

Como hemos expuesto, en las normas que se han descrito, puede observarse como el juez penal puede moderar la obligación de resarcimiento en función del patrimonio del deudor, la propia participación de la víctima o perjudicado en la producción del daño, en el establecimiento de las bases que fundamentan el quantum indemnizatorio y en los supuestos de elección de la responsabilidad criminal. En definitiva, en el ámbito penal, jueces y tribunales tienen amplias facultades de moderación de la responsabilidad civil, dependiendo de ciertas circunstancias, en la fase decisoria, a la hora de resolver el asunto mediante sentencia.

Por otra parte, la responsabilidad civil, al margen de consideraciones sobre la denominada "responsabilidad civil objetiva", se han de dar los cuatro presupuestos típicos a partir de la construcción teórica derivada del artículo 1902 del Código Civil, "El que por acción u omisión causa daño a otro, interviniendo culpa o 
negligencia, está obligado a reparar el daño causado" y que es el exponente normativo del principio alterum non laedere. Estos son:

1) La acción u omisión (“el que por acción u omisión”);

2) El daño ("causa daño a otro");

3) El nexo causal (el daño debe ser consecuencia del hecho);

4) La culpabilidad ("interviniendo culpa o negligencia”).

Por lo que nos interesa, es el daño y su valoración lo que constituye el resarcimiento y el objeto de la obligación de reparar. De esta forma, víctimas y perjudicados son resarcidos por los daños personales o patrimoniales que se les haya inferido. Según la teoría general del daño, este está constituido por el daño emergente y el lucro cesante (además del daño moral), lo cual, en la mayoría de las ocasiones es valorable objetivamente u objetivable. En este sentido, los perjudicados reciben justamente el daño valorado o quantum indemnizatorio. Dicho "valor" viene determinado por la prueba del mismo, de acuerdo con la máxima "quién alega prueba" o onus probandi (carga probatoria). Declarado el hecho, la culpabilidad (civil) y el nexo causal, solo queda determinar el daño a partir de la prueba de parte, y el juez civil decidirá la cuantía de acuerdo con éste último presupuesto; esto es justo lo que determina el principio neminem laedere o alterum non laedere.

A diferencia de lo expuesto, y volviendo a las facultades del juez penal en la fase decisoria, de moderación del quantum, nos cuestionamos si dichas facultades cumplen con el principio; en definitiva si, en términos de justicia, ¿quedan desprotegidos las víctimas y perjudicados por las decisiones del juez penal, en función de sus facultades moderadoras en torno a la responsabilidad civil derivada del delito o falta?

En el ámbito del procedimiento abreviado, concretamente cuando exista "conformidad" entre acusación y defensa, podríamos decir lo mismo. Así, de acuerdo con el artículo 787.1 de la Ley de Enjuiciamiento Criminal, "Antes de iniciarse la práctica de la prueba, la defensa, con la conformidad del acusado 
presente, podrá pedir al Juez o Tribunal que proceda a dictar sentencia de conformidad con el escrito de acusación que contenga pena de mayor gravedad, o con el que se presentara en ese acto, que no podrá referirse a hecho distinto, ni contener calificación más grave que la del escrito de acusación anterior. Si la pena no excediere de seis años de prisión, el Juez o Tribunal dictarásentencia de conformidad con la manifestada por la defensa, si concurren los requisitos establecidos en los apartados siguientes.

El juez, en cualquier caso, habráde aceptar la conformidad, "Si a partir de la descripción de los hechos aceptada por todas las partes, el Juez o Tribunal entendiere que la calificación aceptada es correcta y que la pena es procedente según dicha calificación, dictarásentencia de conformidad. El Juez o Tribunal habrá oído en todo caso al acusado acerca de si su conformidad ha sido prestada libremente y con conocimiento de sus consecuencias" ( artículo 787.2).

Al respecto, sobre la conformidad para los supuestos de procedimiento abreviado, el artículo 784.3 de la Ley de Enjuiciamiento Criminal, "En su escrito, firmado también por el acusado, la defensa podrá manifestar su conformidad con la acusación en los términos previstos en el artículo 787.”

"Dicha conformidad podrá ser también prestada con el nuevo escrito de calificación que conjuntamente firmen las partes acusadoras y el acusado junto con su Letrado, en cualquier momento anterior a la celebración de las sesiones del juicio oral, sin perjuicio de lo dispuesto en el artículo 787.1”.

Respecto a la responsabilidad civil, el escrito de acusación, conforme al artículo 781 de la Ley de Enjuiciamiento criminal, deberáexpresar, en su caso, "la cuantía de las indemnizaciones o se fijarán las bases para su determinación y las personas civilmente responsables".

Por su parte, la Instrucción 2/2009, sobre aplicación del protocolo de conformidad suscrito por la Fiscalía General del Estado y el Consejo General de la Abogacía Español, dice expresamente: “Otra de las tareas esenciales que el Fiscal debe asumir en el marco de la resolución consensuada del procedimiento es la 
protección de la víctima y del resto de los perjudicados por el delito. Esa misión específica del Ministerio Público ha de ser particularmente cuidada a la hora de cerrar el acuerdo de conformidad. La víctima se ha encontrado históricamente ausente y desinformada -cuando no perpleja- acerca del resultado pactado del proceso, sobre todo cuando no estápersonada en él. Por ello, de cara a la negociación de la conformidad el Fiscal procuraráoír previamente a la víctima o perjudicado, aunque no estén personados en la causa, siempre que sea posible y lo juzgue necesario para ponderar correctamente los efectos y el alcance de tal conformidad, y en todo caso cuando por la gravedad o trascendencia del hecho o por la intensidad o la cuantía sean especialmente significativos los intereses en juego, asícomo en todos los supuestos en que víctimas o perjudicados se encuentren en situación de especial vulnerabilidad. Igualmente deberáasegurarse en lo posible que éstos sean informados de la existencia y los términos de la conformidad, una vez pactada, y de sus consecuencias procesales".

\section{EL PRINCIPIO ALTERUM NON LAEDERE EN LA FASE DE EJECUCIÓN DE LA PENA.-}

Previamente, durante la instrucción del proceso, el juez instructor, conforme al artículo 589 de la Ley de Enjuiciamiento Criminal, deberá: "Cuando del sumario resulten indicios de criminalidad contra una persona, se mandarápor el Juez que preste fianza bastante para asegurar las responsabilidades pecuniarias que en definitiva puedan declararse procedentes, decretándose en el mismo auto el embargo de bienes suficientes para cubrir dichas responsabilidades si no prestare la fianza. La cantidad de ésta se fijaráen el mismo auto y no podrá bajar de la tercera parte más de todo el importe probable de las responsabilidades pecuniarias"; sustanciándose la fianza o embargo, en su caso, en pieza separada, conforme al artículo 590 del mismo cuerpo legal. En cualquier caso, será normativa subsidiaria la legislación civil relativa a las fianzas y embargos (artículo 614) ${ }^{7}$.

\footnotetext{
${ }^{7}$ Para el procedimiento abreviado, el artículo 781.1 de la Ley de Enjuiciamiento Criminal, "El escrito de acusación comprenderá, además de la solicitud de apertura del juicio oral ante el órgano que se estime
} 
Establecida la responsabilidad civil mediante sentencia en la fase decisoria, como exponíamos en el primer epígrafe de este trabajo, el caso es que, de acuerdo con el artículo 81.3 del Código Penal para el otorgamiento de la suspensión de la ejecución de la pena, se habrá de haber: "satisfecho las responsabilidades civiles que se hubieren originado, salvo que el Juez o Tribunal sentenciador, después de oír a los interesados y al Ministerio Fiscal, declare la imposibilidad total o parcial de que el condenado haga frente a las mismas".

De acuerdo con MAGRO SERVET, "La redacción del art. 81 CP puede dejar a los perjudicados indefensos si en casos de delitos en los que ha habido un perjuicio económico para víctimas y perjudicados el condenado a pena no superior a dos años alega no disponer de bienes ni dinero para pagar la responsabilidad civil y postula la suspensión de la ejecución de la pena, aspecto este que debería ser objeto de seria reflexión en la reforma del CP; ya que aunque no se trate de postular la recuperación de la prisión por deudas siempre hay que entender que las medidas de suspensión de la ejecución y su sustitución deben aplicarse cuando los perjudicados no reclamen o hayan cobrado, pero no cuando exista una responsabilidad civil por satisfacer. Pero el texto actual abre una puerta a alegar insolvencia y reclamar, al mismo tiempo, beneficios de este tipo, lo que deja a los perjudicados en difícil situación”; en este sentido, -continua el autor-, "resulta absurdo conceder la suspensión si esta responsabilidad civil no se ha abonado, salvo que se establezca un aplazamiento en el pago de la responsabilidad civil y se fije en el auto la condición de que en el caso de que se deje de abonar alguna de las cuotas se revocaría la medida de suspensión"».

Estamos totalmente de acuerdo con dicho autor, se hace necesario una seria reflexión que abogue por la reforma del Código Penal en este sentido. Pues si en la

competente y de la identificación de la persona o personas contra las que se dirige la acusación, los extremos a que se refiere el artículo 650. La acusación se extenderáa las faltas imputables al acusado del delito o a otras personas, cuando la comisión de la falta o su prueba estuviera relacionada con el delito. También se expresarán la cuantía de las indemnizaciones o se fijarán las bases para su determinación y las personas civilmente responsables, asícomo los demás pronunciamientos sobre entrega y destino de cosas y efectos e imposición de costas procesales (...)".

${ }^{8}$ MAGRO SERVET, V., "La no suspensión de la ejecución de la pena en caso de impago de la responsabilidad civil”, Práctica de Tribunales, Nº111, Sección Práctica Procesal, Noviembre-Diciembre 2014, Editorial LA LEY, (edición digital). 
fase decisoria, la responsabilidad civil puede ser modulada por el juez penal en virtud de las facultades que les otorgan las normas expuestas más arriba, no tiene sentido que, para las víctimas y perjudicados queden mermadas sus expectativas no solo en el ámbito económico o patrimonial sino en el ámbito de la prevención general del delito por la suspensión de la medida de pena privativa de libertad.

Pero el panorama no es alentador, así, en el Proyecto de Reforma del Código Penal $^{9}$, se modifica el artículo 86 dándole una nueva redacción: "El Juez o Tribunal revocarála suspensión y ordenarála ejecución de la pena cuando el penado (...) 4) Facilite información inexacta o insuficiente sobre el paradero de bienes u objetos cuyo comiso hubiera sido acordado; no décumplimiento al compromiso de pago de las responsabilidades civiles a que hubiera sido condenado, salvo que careciera de capacidad económica para ello; o facilite información inexacta o insuficiente sobre su patrimonio, incumpliendo la obligación impuesta en el artículo 589 de la Ley de Enjuiciamiento Civil”. Es decir, si para la suspensión de la ejecución de la pena, el juez penal hubiera atendido una petición de aplazamiento de la responsabilidad civil y llegado el supuesto de su cumplimiento, el condenado no atendiera dichos pagos, aún así, no podrá revocarse si acreditara la falta de medios.

Existen, sin embargo, opiniones diferentes en la doctrina que abogan por el mantenimiento de la aplicación de la medida de suspensión de la pena, no obstante no haber atendido la responsabilidad civil. En este sentido, LACUEVA BERTOLACCI, al comentar el Proyecto de Reforma del Código Penal, dice que un diferente tratamiento de la suspensión para quienes puedan atender la responsabilidad civil por tener los recursos necesarios frente a aquellos que no tengan patrimonio suficiente, podría vulnerar el artículo 14 de la Constitución, así como el artículo 21.1 de la Carta de los Derechos Fundamentales de la Unión

\footnotetext{
${ }^{9}$ Boletín Oficial de las Cortes Generales 4.10.2013. Proyecto de Ley Orgánica por la que se modifica la Ley Orgánica 10/1995, de 23 de noviembre, del Código Penal, Exposición de Motivos V, "Con esta misma finalidad, se modifica el régimen de valoración del cumplimiento de la responsabilidad civil. El sistema actual de comprobación previa resulta ineficaz y poco ágil, y dificulta que las decisiones sobre la suspensión de la pena puedan ser adoptadas en el mismo momento en que se dicta sentencia. Por ello, se introduce un sistema inverso al actual: el pago de la responsabilidad civil (y también, que se haya hecho efectivo el comiso acordado por los Jueces o Tribunales) continúa siendo un presupuesto de la suspensión de la ejecución; pero es la ocultación de bienes o el hecho de no aportar información sobre los disponibles o de no facilitar el decomiso acordado lo que determina la revocación de la suspensión yaacordada.".
} 
Europea ${ }^{10}$ puesto que "implica una discriminación, por parte de la Administración de Justicia, a un ciudadano atendiendo al patrimonio (bienes y derechos) que ostente, con una consecuencia tan importante como es la privación de libertad"11.

Dichos argumentos, esgrimidos por este autor, podrían apoyarse también en los propios fines que ostentan la suspensión de la ejecución de la pena, como ha declarado el Tribunal Constitucional: "los preceptos del Código Penal puestos indirectamente en tela de juicio se mueven dentro del perímetro diseñado constitucionalmente como campo de juego de la política criminal, cuya cristalización en normas corresponde a las Cortes Generales. Efectivamente, la mal llamada condena condicional, que fue incorporada a nuestro ordenamiento jurídico por la Ley de 17 Mar. 1908, dentro de un generalizado movimiento de opinión en los países de nuestro entorno, tenía una finalidad explícita, a la cual sirve también la remisión condicional de la condena, en expresión más precisa del Código Penal, que ha heredado la institución. Una vez comprobada la ineficacia de las penas cortas de privación de libertad para conseguir la corrección del reo e incluso el riesgo de contagio que conlleva la convivencia de quien ha delinquido ocasionalmente con los delincuentes habituales o profesionales, se arbitrócomo «ensayo»en su día, que se ha demostrado positivo, la suspensión del cumplimiento de la condena impuesta, si se trata de «primarios»(una primera vez), para conseguir así, mediante la doble presión

\footnotetext{
10“'Se prohíbe toda discriminación, y en particular la ejercida por razón de sexo, raza, color, orígenes étnicos o sociales, características genéticas, lengua, religión o convicciones, opiniones políticas o de cualquier otro tipo, pertenencia a una minoría nacional, patrimonio, nacimiento, discapacidad, edad u orientación sexual".

${ }^{11}$ Por todo, LACUEVA BERTOLACCI, R., "La revocación de la suspensión de la ejecución de la pena privativa de libertad en la reforma del Código Penal”, Diario La Ley, N8066, Sección Tribuna, 19 Abr. 2013, Año XXXIV, Editorial LA LEY, (edición digital); "En el art. 80.2.3. ${ }^{a}$ ACP la plena satisfacción de la responsabilidad civil o el compromiso de verificarlo en los plazos que se determinen, sin excepción alguna, constituyen requisitos ineludibles para que el condenado obtenga el beneficio de la suspensión de la ejecución de la pena privativa de libertad. Por este motivo, se prevécomo causa de revocación —entre otras-que el condenado deje de abonar la indemnización en los plazos fijados o que obstaculice la reparación o el resarcimiento. Sin embargo, esta previsión o diferente tratamiento para la concesión de la suspensión entre quienes dispongan de recursos económicos y quienes no podría vulnerar tanto el art. 14 CE como el art. 21.1 de la Carta de los Derechos Fundamentales de la Unión Europea puesto que implica una discriminación, por parte de la Administración de Justicia, a un ciudadano atendiendo al patrimonio (bienes y derechos) que ostente, con una consecuencia tan importante como es la privación de libertad. En mi opinión, si el legislador opta por el mantenimiento del beneficio de la suspensión para los delincuentes primarios debería establecerse con independencia de que satisfaga la responsabilidad civil derivada del delito. Otra cuestión sería estudiar que la reparación del daño a la víctima del delito implicara una reducción mayor de la pena a la actual como atenuante, pero que no tuviera incidencia una vez iniciado el proceso de ejecución".
} 
de la gratitud por el beneficio y el temor de su pérdida, la rehabilitación, con una función profiláctica de la criminalidad"12.

Una vez vistos los argumentos en pro del principio de igualdad y los fundamentos de la suspensión de la ejecución de la pena privativa de libertad, debemos plantearnos posibles vías de solución.

\section{POSIBLE SOLUCIONES. DE LEGE FERENDA.-}

Como vimos al principio de este trabajo, el artículo 81 del Código Penal al enunciar las condiciones que deben apreciarse por el Juzgador a la hora de la aprobación de la suspensión de la ejecución de la pena, deberían haberse satisfecho "las responsabilidades civiles que se hubieren originado, salvo que el Juez o Tribunal sentenciador, después de oír a los interesados y al Ministerio Fiscal, declare la imposibilidad total o parcial de que el condenado haga frente a las mismas".

De esta forma, decíamos que podría suceder que un condenado no cumpliere ningún tipo de sanción (privación de libertad) ni reparar el daño producido a víctima y/o perjudicados, lo cual atenta contra el principio alterum non laedere. La solución no es fácil, pues es cierto que, de acuerdo con el principio de igualdad, el necesario cumplimiento de la responsabilidad civil para la aprobación de la suspensión de la pena sin ningún tipo de excepción, premia, por así decirlo, a aquellos que tienen recursos económicos frente a quienes no los poseen.

\footnotetext{
${ }^{12}$ STC 209/1993, de 28 junio; sobre la no ejecución de sentencias, STC 18/1997, de 10 de febrero, “(...) Este Tribunal ha afirmado, y ahora lo debemos reiterar, que la ejecución de las Sentencias forma parte del derecho a la tutela efectiva de los Jueces y Tribunales, ya que en caso contrario las decisiones judiciales y los derechos que en las mismas se reconocen o declaran no serían otra cosa que meras declaraciones de intenciones sin alcance práctico ni efectividad alguna. Más concretamente, el derecho a la ejecución impide que el órgano judicial se aparte, sin causa justificada, de lo previsto en el fallo que ha de ejecutar, o que se abstenga de adoptar las medidas necesarias para proveer a la ejecución de la misma, cuando ello sea legalmente exigible (SSTC 125/1987, 215/1988, 153/1992, entre otras). (...) una decisión de no ejecución de una Sentencia habráde apoyarse en la concurrencia de una causa prevista por una norma legal, pero interpretada a su vez en el sentido más favorable a tal ejecución, sin que sea constitucionalmente válida la inejecución salvo que asíse decida expresamente en resolución motivada, en aplicación de una causa prevista por una norma legal y no interpretada restrictivamente (SSTC 155/1985, 151/1993)".
} 
En este orden de ideas, una solución que nos parece muy acertada, se encuentra en el ámbito del Derecho penal juvenil. Así, el artículo 19 de la Ley Orgánica $5 / 2000$, de 12 de enero, reguladora de la responsabilidad penal de los menores (en adelante, LORPM), regula el sobreseimiento del expediente por conciliación o reparación entre el menor y la víctima. En este sentido, el Ministerio Fiscal ${ }^{13}$ podrá desistir de la continuación del expediente, atendiendo a la gravedad y circunstancias de los hechos y del menor, de modo particular a la falta de violencia o intimidación graves en la comisión de los hechos, y a la circunstancia de que además el menor se haya conciliado con la víctima o haya asumido el compromiso de reparar el daño causado a la víctima o al perjudicado por el delito, o se haya comprometido a cumplir la actividad educativa propuesta por el equipo técnico en su informe. El desistimiento en la continuación del expediente sólo seráposible cuando el hecho imputado al menor constituya delito menos grave o falta. A efectos de lo dispuesto en el apartado anterior, se entenderáproducida la conciliación cuando el menor reconozca el daño causado y se disculpe ante la víctima, y ésta acepte sus disculpas, y se entenderápor reparación el compromiso asumido por el menor con la víctima o perjudicado de realizar determinadas acciones en beneficio de aquéllos o de la comunidad, seguido de su realización efectiva. Todo ello sin perjuicio del acuerdo al que hayan llegado las partes en relación con la responsabilidad civil.

A partir de la dicción de dicho artículo 19.1, de acuerdo con su punto $4^{\circ}$, una vez producida la conciliación o cumplidos los compromisos de reparación asumidos con la víctima o perjudicado por el delito o falta cometido, o cuando una u otros no pudieran llevarse a efecto por causas ajenas a la voluntad del menor, el Ministerio Fiscal darápor concluida la instrucción y solicitarádel Juez el sobreseimiento y archivo de las actuaciones, con remisión de lo actuado.

\footnotetext{
${ }^{13}$ Artículo 61.1 LORPM, "La acción para exigir la responsabilidad civil en el procedimiento regulado en esta Ley se ejercitarápor el Ministerio Fiscal, salvo que el perjudicado renuncie a ella, la ejercite por símismo en el plazo de un mes desde que se le notifique la apertura de la pieza separada de responsabilidad civil o se la reserve para ejercitarla ante el orden jurisdiccional civil conforme a los preceptos del Código Civil y de la Ley de Enjuiciamiento Civil”.
} 
La mediación penal será dirigida por los miembros del equipo técnico, quienes realizarán dichas funciones, con información al Ministerio Fiscal de los compromisos adquiridos y de su grado de cumplimiento.

En los casos en que el menor no cumpliera la reparación o la actividad educativa acordada, el Ministerio Fiscal continuarála tramitación del expediente.

Otro tema es saber si, dada la responsabilidad solidaria de padres, tutores, acogedores y guardadores legales o de hecho, podrán, en exclusiva, asumir el compromiso o conciliar con las víctimas o perjudicados sin intervención del menor $^{14}$.

Del mismo modo, específicamente, el artículo 4 LORPM, dispone que el Ministerio Fiscal y el Juez de Menores velarán en todo momento por la protección de los derechos de las víctimas y de los perjudicados por las infracciones cometidas por los menores; con derecho a perforación e información, conforme a los artículos 109 y 110 de la Ley de Enjuiciamiento Criminal, renuncia o reserva de la acción civil. En especial, cuando el Ministerio Fiscal, en aplicación de lo dispuesto en el artículo 18 de esta Ley, desista de la incoación del expediente deberáinmediatamente ponerlo en conocimiento de las víctimas y perjudicados haciéndoles saber su derecho a ejercitar las acciones civiles que les asisten ante la jurisdicción civil ${ }^{15}$.

\footnotetext{
${ }^{14}$ Artículo 61.3 LORPM, "Cuando el responsable de los hechos cometidos sea un menor de dieciocho años, responderán solidariamente con él de los daños y perjuicios causados sus padres, tutores, acogedores y guardadores legales o de hecho, por este orden. Cuando éstos no hubieren favorecido la conducta del menor con dolo o negligencia grave, su responsabilidad podráser moderada por el Juez según los casos".

${ }^{15}$ Artículo 4 LORPM,“Derechos de las víctimas y de los perjudicados. El Ministerio Fiscal y el Juez de Menores velarán en todo momento por la protección de los derechos de las víctimas y de los perjudicados por las infracciones cometidas por los menores.

De manera inmediata se les instruiráde las medidas de asistencia a las víctimas que prevéla legislación vigente.

Las víctimas y los perjudicados tendrán derecho a personarse y ser parte en el expediente que se incoe al efecto, para lo cual el secretario judicial les informaráen los términos previstos en los artículos 109 y 110 de la Ley de Enjuiciamiento Criminal, instruyéndoles de su derecho a nombrar abogado o instar el nombramiento de abogado de oficio en caso de ser titulares del derecho a la asistencia jurídica gratuita. Asimismo, les informaráde que, de no personarse en el expediente y no hacer renuncia ni reserva de acciones civiles, el Ministerio Fiscal las ejercitarási correspondiere.

Los que se personaren podrán desde entonces tomar conocimiento de lo actuado e instar la práctica de diligencias y cuanto a su derecho convenga.
} 
De esta forma, el compromiso de reparar, o la propia reparación del daño causado, emerge como eje fundamental de cumplimiento y/o conciliación víctima (perjudicado)-victimario. Esta solución podría aplicarse a la hora de aprobar o no la suspensión de la ejecución de la pena.

Como expone VALLS RIUS, "La Justicia restaurativa es una nueva vía de intervención en conflictos penales, que promueve un mayor protagonismo de las partes en la gestión de las consecuencias producidas a raíz del delito. La Justicia restaurativa, que se estáaplicando de forma creciente en toda Europa, pone el acento más en la reparación voluntaria a la víctima que en el castigo, ofreciendo al autor de los hechos la posibilidad de reparar, por símismo, el daño producido. La mediación en el ámbito penal es uno de los métodos más extendidos de Justicia restaurativa y supone crear un espacio en el que víctima y autor, con la intervención del mediador, tienen la oportunidad de tratar del hecho delictivo y participar activamente en la búsqueda de una respuesta que compense el daño producido y propicie un proceso de reflexión en el autor, que le permite tomar conciencia real del daño que su conducta ha ocasionado. El autor tiene la oportunidad de pasar de ser una figura pasiva del castigo a actuar positivamente para compensar el daño causado a la víctima e indirectamente a la propia comunidad" ${ }^{\prime 6}$.

Sin perjuicio de lo anterior, el secretario judicial deberácomunicar a las víctimas y perjudicados, se hayan o no personado, todas aquellas resoluciones que se adopten tanto por el Ministerio Fiscal como por el Juez de Menores, que puedan afectar a sus intereses.

En especial, cuando el Ministerio Fiscal, en aplicación de lo dispuesto en el artículo 18 de esta Ley, desista de la incoación del expediente deberáinmediatamente ponerlo en conocimiento de las víctimas y perjudicados haciéndoles saber su derecho a ejercitar las acciones civiles que les asisten ante la jurisdicción civil.

Del mismo modo, el secretario judicial notificarápor escrito la sentencia que se dicte a las víctimas y perjudicados por la infracción penal, aunque no se hayan mostrado parte en el expediente".

16“'Debe no obstante advertirse que la justicia restaurativa no es un término equivalente al de mediación. La mediación seráuno de los instrumentos posibles para hacer efectiva esa justicia restaurativa, contando con la participación de la víctima en la gestión del conflicto, y haciendo que sean ella y el infractor quienes logren alcanzar un acuerdo dirigido a reparar/restaurar el daño. Sin embargo, la mediación no serála única vía para lograr esa justicia restaurativa. Cabe pensar también — desde una perspectiva de futuro y no atendiendo al actual marco legal—que pese a la intervención de la víctima no se alcance el acuerdo mediador y que sea la autoridad competente la que, atendiendo a las circunstancias concurrentes, opte por imponer ciertas medidas propias de la justicia restaurativa. Tendríamos con ello una manifestación de justicia restaurativa pero no de mediación", VALL RIUS, A., "El desarrollo de la Justicia restaurativa en Europa: Estudio comparado con la legislación española”, Diario La Ley, Nº528, Sección Doctrina, 18 Jul. 2006, Editorial LA LEY, (edición digital). 


\section{Doctrina y Jurisprudencia}

Por tanto, entendemos que, de lege ferenda, en el ámbito de la responsabilidad civil derivada de delito o falta, a partir de soluciones en el ámbito de la justicia restaurativa mediante la mediación o mediante la reparación directa víctimacondenado, para la suspensión de la ejecución de la pena, en el caso de que no pudiera verificarse por el condenado en el momento, se establecieran mecanismos de reparación futuros o incluso la mediación obligatoria. 